\title{
Evidential Modals at the Semantic- Argumentative Interface: Appearance Verbs as Indicators of Defeasible Argumentation
}

\author{
Elena Musi
}

Università della Svizzera italiana (Istituto di Studi italiani), Via Lambertenghi 10A CH-6904

Lugano (Switzerland)

elena.musi@usi.ch

\begin{abstract}
This contribution aims at providing an argumentative method to account for epistemic modality and evidentiality. I claim that these two linguistic categories can work as semantic components of defeasible argumentative schemes based on classification processes. This kind of approximate reasoning is, in fact, frequently indicated by appearance verbs which signal that the inferred standpoint is conceived by the speaker as uncertain (epistemic value) due to the deceiving nature of perceptual data (evidential value). Drawing from an analysis at the semantic-argumentative interface, the way in which prototype theory sheds light on the processes of meaning construction underlying defeasible arguments from definition is also shown.
\end{abstract}

Résumé: This contribution aims at providing an argumentative method to account for epistemic modality and evidentiality. I claim that these two linguistic categories can work as semantic components of defeasible argumentative schemes based on classification processes. This kind of approximate reasoning is, in fact, frequently indicated by appearance verbs which signal that the inferred standpoint is conceived by the speaker as uncertain (epistemic value) due to the deceiving nature of perceptual data (evidential value). Drawing from an analysis at the semantic-argumentative interface, the way in which prototype theory sheds light on the processes of meaning construction underlying defeasible arguments from definition is also shown.

Keywords: appearance verbs, argument from definition, Argumentum Model of Topics, epistemic modality, evidentiality defeasible reasoning, prototype theory, semantics-argumentation interface.

\section{Introduction}

This contribution proposes an argumentative method for analyzing epistemic modality and evidentiality ${ }^{1}$ commencing

\footnotetext{
${ }^{1}$ Evidentiality is the linguistic category which "refers to the reasoning processes that lead to a proposition" while epistemic modality "evaluates the likelihood that a proposition is true" (Cornillie 2009, p. 47).
}

(C) Elena Musi, Informal Logic, Vol. 34, No. 4 (2014), pp.417442. 
from the interface between semantics and argumentation ${ }^{2}$.

Starting from the analysis of appearance verbs, the aim is to show how their evidential and epistemic values can be mapped into the argumentative reconstruction of the reasoning they indicate. Appearance verbs frequently indicate defeasible argument schemes based on classification processes: they signal that the inferred standpoint is conceived by the speaker as uncertain (epistemic value) due to the deceiving nature of perceptual data which function as premises (evidential value). My working hypothesis is that a deep semantic analysis of appearance verbs is needed to shed light on the complexity of the processes of categorization exploited in plausible reasoning. The importance of semantics for a theory of argumentation has been recently recognized in the study of analytical reconstructions (van Eemeren and Grootendorst 2004, van Eemeren 2010) and in the study of implicit premises (Rocci 2005, Bigi and Greco Morasso 2012, Miecznikowski, Rocci and Zlatkova 2013 and Miecznikowski and Zlatkova, to appear). In particular, the role of the lexical Italian modals dovere ('must') and potere ('can') as argumentative indicators has been widely investigated by Rocci $(2012,2013)$ in the context of economical financial news.

The theoretical and methodological frameworks I refer to are the Congruity Theory approach (Rigotti and Rocci 2001, Rigotti 2005, Rigotti, Rocci and Greco 2006) for the semantic analysis and the Argumentum Model of Topics (Rigotti and Greco 2010) for argumentative reconstructions. The usefulness of these two models to tackle the semantic-argumentative interface is respectively explained in sections 2 and 3 .

As a case study, I focus on the Italian verb apparire ('to appear') drawing on 31 occurrences of the verb contained in art exhibition reviews downloaded from the Italian site Mostreinmostra. The choice of exhibition reviews as a source of data is motivated by the argumentative nature of this text genre. As underlined by Miecznikowski (to appear), the aim of an exhibition review is to help readers decide whether that exhibition is well worth a visit or not. To this purpose, reviewers report their firsthand experience as an argument in support of the overall evaluation. In the case of exhibition reviews, the

\footnotetext{
${ }^{2}$ This study is part of the broader research project "From perception to inference. Evidential, argumentative and textual aspects of perception predicates in Italian", supported by the Swiss National Foundation (grant n.141350, see http://www.perc-inferenza.ch) and directed by Johanna Miecznikowski and Andrea Rocci at USI (Università della Svizzera Italiana).
}

(C) Elena Musi, Informal Logic, Vol. 34, No. 4 (2014), pp.417442. 
Interface

visual character of the reviewed object favours the occurrences of appearance verbs both in the description of the reviewer's impression in front of the works of art and in evaluative utterances about the exhibition itself.

The first section of the study is devoted to the semantic analysis, while the second part deals with argumentative reconstructions. In section 2, I explain why the verb apparire functions in its inferential uses, which have proved to be primarily abductive, as an indicator of defeasible argumentation. On the one hand, the verb presupposes a set of information sources in its semantic structure which signals the presence of premises from which a proposition is inferred (evidential value). On the other hand, it points to the fact that the inferred proposition is presented by the speaker as plausible, but not certain (epistemic-modal value). This lack of certainty can be traced back to the illusory nature of perception, which is at the basis of the critical questions that participants to the event raise from the so called argument from appearance (Walton 2006). The lexicalization of this type of categorization is compatible with a conceptualization of our processes of meaning construction as based on a principle of analogy and similarity more than on a principle of identity. On this basis, in section 4, after having described some basic principles of prototype theory, I propose two argumentative reconstructions based on the socalled "argument from prototype definition" in order to show the explanatory power of this semantic theory for the analysis of defeasible arguments. ${ }^{3}$

\section{Apparire's semantic analysis}

This section is dedicated to the identification of the participants in the event expressed by apparire (linguistic argument structure), on the basis of the "Congruity Theory"4 approach (Rigotti and Rocci 2001, Rigotti 2005, Rigotti, Rocci and Greco 2006). Following this semantic-pragmatic theory, discourse units can be conceived in terms of predicative-argument

\footnotetext{
${ }^{3}$ Framenet is a free access lexical database elaborated by the International Computer Science Institute in Berkeley (https://framenet.icsi.berkeley.edu/fndrupal/).

${ }^{4}$ The term congruity traces back to the notion of symploké (<Greek "sympléko", 'interwining') as used in Plato' Sophist (261.d.4 - 262.e.2) where the philosopher metaphorically represents discourse as a living body which cannot be dismembered.
}

(C) Elena Musi, Informal Logic, Vol. 34, No. 4 (2014), pp.417442. 
structures whose combination gives rise to meaningful verbal communication through language compositionality. This approach is pragmatic both in a broad and an etymological sense: it focuses on the relevance of contextual factors required to interpret the information encoded by linguistic lexicon and it considers verbal communication as action since the meaning of an utterance "coincides with its intended effects, that is to say with the change it brings about in the context-yet more precisely in the intersubjectivity of the interlocutors" (Rigotti 2005, p. 77).

Predicates $(<$ Latin praedicatum $<$ Greek kategoria $=$ kata, 'about' and agoreuo, 'to speak') are those actions, events, properties which speak about the mode of being of an argument. The class of arguments includes individuals, states of affairs, and events that are affected by those modes of being. The semantic structure of a predicate is characterized by two components: presuppositions, requirements that the predicate imposes on its argument places according to number, quality, and order (argument structure), and entailments, which refer to what occurs when the predicate is true of its arguments. The presuppositions are conditions of meaningfulness which characterize both the cases in which the predicate is affirmed and those in which the predicate is negated. Differently, the semantic implications of the predicate do not hold when the predicate is negated.

The advantages offered by this framework for the study of the semantic- argumentative interface are twofold: on the one hand a semantic approach to argument structure, as opposed to a syntactic one (Hale and Keyser 2002), recognizes as arguments also elements which are not syntactically expressed but logically-semantically implied; these arguments are conditions necessary to interpret the meaning of the predicate and guarantee the text's coherence. On the other hand, compared to other semantic approaches (Pustejovsky 1995), it highlights the interrelations between presuppositions and lexical meaning (entailments) enabling the reconstruction of inferential processes. The presuppositions triggered by the predicate function at a pragmatic level as Searlian felicity conditions of the utterance containing the predicate. In this way, the lexical predicate functions as a high level pragmatic predicate called a "connective predicate", guaranteeing the coherence of the text it is part of. The applicability of such an approach in argumentative terms is straightforward: "the pragmatic conditions of argumentation and the logical requirements of the particular inference schemes employed are analyzed as part of

(C) Elena Musi, Informal Logic, Vol. 34, No. 4 (2014), pp.417442. 
the presuppositions of the connective predicate at issue" (Rigotti 2005, p. 75). The choice of adopting the Congruity Theory approach is justified by the fact that, compared to other approaches to discourse relations, it encompasses both the semantic and the pragmatic-argumentative level in a unified account.

From the analysis of the 31 occurrences of the verb in the chosen corpus, two basic meanings of the verb have emerged. The first one is traceable to the etymon of the verb (apparire < Lat. apparêre 'to come out, to become visible, to come to light') indicating the appearance of an object entering the perceiver's visual field:

1. Poi un po' di calma ed eccoti apparire davanti un paio di "pezzi da novanta" come la Madonna con il bambino, serafini e cherubini ed il Cristo morto, entrambi provenienti da Brera. (Review, Mostreinmostra, Exhibition: "Mantegna", Verona)

"Then, after having waited a bit, there appears in front of us a couple of 'big pieces' like the Madonna and child, seraphim and cherubim and the Dead Christ, both from Brera".

In these cases, apparire functions as a two place predicate where $\mathrm{x}_{1}$ is the object which appears, and $\mathrm{x}_{2}$ is the perceiver:

Apparire $\left(\mathrm{x}_{1}, \mathrm{x}_{2}\right)$

Presuppositions:

$\mathrm{x}_{1}: \mathrm{X}_{(\mathrm{x} 1)} \wedge \neg \operatorname{see}\left(\mathrm{x}_{2}, \mathrm{x}_{1}\right) \mathrm{t}-1$

$\mathrm{x}_{2}$ : animate $\left(\mathrm{x}_{2}\right) \wedge \forall \mathrm{y} \in\left(\mathrm{X}(\mathrm{y}) \rightarrow \bigvee_{\mathrm{a}}\left(\mathrm{x}_{2}\right.\right.$, see $\left.\left.\left(\mathrm{x}_{1}, \mathrm{y}\right)\right)\right)$

Entailments

see $\left(\mathrm{x}_{2}, \mathrm{x}_{1}\right)_{\mathrm{t}} \quad \mathrm{X}$ : class of concrete, visible objects

The predicate imposes constraints not only on the number, but also on the quality of the arguments: $\mathrm{x}_{1}$ has to belong to the class of concrete, visible objects which have not be seen by $\mathrm{x}_{2}$ at the moment of speaking; $x_{2}$, in turn, must exist, be animate, and be capable of seeing the eventuality $\mathrm{x}_{1}$. Moreover, the semantics of

(C) Elena Musi, Informal Logic, Vol. 34, No. 4 (2014), pp.417442. 
apparire as a percept oriented verb ${ }^{5}$ presuppose that $\mathrm{x}_{1}$, positioned before or after the verb, works as the grammatical subject of the predicate. The presuppositions imposed by the predicate as represented in the scheme are hyperonyms of the characteristics of "us" and "a couple of big pieces". When used as in example 1 the verb is attested in descriptive rather than argumentative contexts. The reviewer, in order to describe the exhibition, leads the reader along a fictive visit: the verb apparire is at the same time used to express the perceptual impact of a work of art and to introduce a new topic in the discourse universe.

In its other occurrences, especially in copulative constructions, the verb conveys an inferential value signalling that the proposition expressed by the speaker is based on a set of information sources. Indeed, this inferential meaning has been crosslinguistically recognized in studies (Col 2006, Cornillie 2009, Gisborne 2007, Diewald and Smirnova 2010) about appearance verbs as markers of evidentiality.

As remarked upon by Rocci regarding necessity modals, evidentiality plays an important role in discourse relations since it "can constrain the interpretation of their immediate co-text allowing the addressee to establish an argumentative relation between the utterance in which they appear and co-textually recoverable evidence" (Rocci 2012, p. 2129). The nature of this relation has not been deeply investigated by linguists and lacks a systematic theoretical account. In this regard, I claim that the inferential relations in question can be classified as abductive, drawing from the following definition of abductive reasoning provided by Walton: "abductive reasoning is a kind of guessing by a process of forming a plausible hypothesis that explains a given set of facts or data" (2001, p. 143). The conclusion drawn from abductive inference is, hence, more fallible than those resulting from other kinds of inferences (inductive and deductive). In the literature, abductive inferences are considered to be the same as inferences to the best explanation (Harman 1965, Josephson and Josephson 1994, Douven and Verbrugge 2010) which are conceived as more or less likely depending on several factors. In the following sections I will show how appearance verbs, behaving as markers of evidentiality, impose constraints on the information sources at the basis of the uttered proposition. In pragmatic terms, the verb apparire, presupposing

\footnotetext{
${ }^{5}$ Percept oriented verbs differ from perceiver-oriented verbs (for example the verb to see), in which the perceiver occupies the subject position.
}

(C) Elena Musi, Informal Logic, Vol. 34, No. 4 (2014), pp.417442. 
in its argument structure a set of information sources, gives the reader the instruction to look in the co-text for a set of premises at the basis of the uttered proposition $p$ :

2. è il caso di Fanny Churberg che realizza il dipinto Rocce di granito friabile (1871, Helsinki, Ateneumin Taidemuseo Suomen Kansalissgalleria) in cui la natura non affatto idilliaca appare invece brutale e diretta, nella scoscesità dei massi dipinti, nei giochi di luce ed ombra, e con l'effetto della profondità dato da un uso sapiente del bianco e del grigio. (Review, Mostreinmostra, Exhibition: "Munch e lo spirito del nord", Udine)

"It is the case of Fanny Churberg who painted friable Granite rocks (1871 Helsinki, Suomen Ateneumin Taidemuseo Kansalissgalleria) in which [nature, not idyllic at all, appears rather brutal and direct] proposition [in the steep boulders depicted in the play of light and shadow, and the effect of depth given by a wise use of white and gray] information source

Even if in 2, the information source is of a perceptual nature, the speaker does not directly witness a brutal nature but he infers that this impression matches the figurative intention of the painter from a series of depicted details. Since these details are overtly expressed, they function as intersubjective sources of information which the writer is invited to look at in order to understand and/or agree with the writer's qualification. The reviewer's communicative intention is probably to make the reader focus on the painting's most salient peculiarities, which will be exploited as a ground to express an overall evaluation of the exhibition at the end of the review.

The role of the reader's knowledge in making an interpretative hypothesis (abductive inference) is more apparent in the following example, in which the recognition of iconographical roots of the Dinner in the sixteenth's century Lombard paintings is due to the reviewer's personal artistic notions:

3. Questa prima Cena appare debitrice della tradizione pittorica lombarda del Cinquecento [...]: attorno ad una tavola imbandita, alla presenza di un oste, Cristo giovane e imberbe - spezza il pane e col gesto benedicente si rivela ai due attoniti pellegrini che reagiscono al miracolo con accenti plateali. (Review, Mostreinmostra, Exhibition: "Caravaggio ospita Caravaggio", Milano)

(C) Elena Musi, Informal Logic, Vol. 34, No. 4 (2014), pp.417442. 
"This first Dinner appears to be retraceable to the Lombard tradition of painting of the sixteenth century [...] around a dinner table, in the presence of an innkeeper, Christ - young and beardless -breaks the bread and with the gesture of blessing is revealed to the two astonished pilgrims who react to the miracle with blatant accents."

The semantic difference between the strictly perceptual use (see example 1) and the inferential uses of apparire is reflected in a difference both in the number and the ontological types of the presupposed argument places. Apparire's argument structure in examples 2 and 3 can be formalized as follows:

Apparire $\left(\mathrm{x}_{1}, \mathrm{x}_{2}, \mathrm{x}_{3}, \mathrm{~B}_{\text {Dox }}\right)$

Presuppositions

$\mathrm{x}_{1}$ : eventuality $\left(\mathrm{x}_{1}\right) \wedge \mathrm{X}_{\mathrm{n}}\left(\mathrm{x}_{1}\right) \wedge$ see $\left(\mathrm{x}_{2}, \mathrm{x}_{1}\right)$

$\mathrm{x}_{2}$ : animate $\left(\mathrm{x}_{2}\right) \wedge \forall \mathrm{y} \in\left(\mathrm{X}(\mathrm{y}) \rightarrow \bigvee_{\mathrm{a}}\left(\mathrm{x}_{2}\right.\right.$, see $\left.\left.\left(\mathrm{x}_{1}, \mathrm{y}\right)\right)\right)$

$\mathrm{x}_{3}$ : eventuality $\left(\mathrm{x}_{3}\right) \wedge \mathrm{X}_{\mathrm{n}^{\prime}}\left(\mathrm{x}_{3}\right)$

$B_{\text {Dox }}$ : background set of presumptions associating eventualities of class $X_{n}$ with eventualities of class $X_{n}$,

Entailments

$\square\left(\left(\left\{p_{x 1}\right\} \cup B_{\text {Dox }}\right) \rightarrow p_{x}\right) \quad X_{n}$ : class of eventualities which can be visually experienced

The argument $\mathrm{x}_{2}$ is not overtly expressed in the text but it is presupposed by the semantics of the verb: working as an epistemic modal, apparire is performative and hence necessarily defined in relation to a human being who commits himself to the truth of the uttered proposition. The first argument has to be an eventuality of the class $X_{n}$ which can be experienced by $x_{1}$ through the sense of sight. Ontologically speaking, it can be a concrete object, like in 2 and 3, or an event such as a football match or a theatre show. The violation of the condition imposed by the predicate on $\mathrm{x}_{1}$ would produce incongruity and hence nonsense (* "Music appears to be"). In example $3, \mathrm{x}_{1}$ are the sources of information through which the speaker describes the painting with its iconographical features. The eventuality $\mathrm{x}_{3}$ corresponds to what appears to $\mathrm{x}_{2}$ as a possible state of affairs. In its evidential-inferential uses, apparire functions as a

(C) Elena Musi, Informal Logic, Vol. 34, No. 4 (2014), pp.417442. 
connective predicate signalling that the proposition corresponding to the occurrence of the eventuality $\mathrm{x}_{3}$ is inferred as a conclusion from a set of information sources which can be conceived of in argumentative terms as signs.

However, the proposition denoting the eventuality $\mathrm{x}_{1}$ alone does not suffice to allow the inferential process as the basis of the proposition asserting the appearance. To obtain $\mathrm{px}_{3}$, a second unstated premise which clarifies the relation between the sources of information and the conclusion must be supplied. In example 3, a reconstructed implicit premise would state that the iconographical features described by the author are typical of the Lombard Sixteenth century tradition of painting. What is presupposed in the argument structure of the verb is, hence, the existence of a class of presumptions associating the eventualities $\mathrm{x}_{1}$ and $\mathrm{x}_{3}$. The $\mathrm{B}_{\text {Dox }}$ argument, which reveals the modal nature of apparire, can be traced back to Kratzer's (1981) Relative Modality ${ }^{6}$ following which, modals are relational predicates whose components are prejacent (the proposition in scope) and a set of propositions called conversational background. The modal relation expressed by apparire is that of possibility which is defined by the compatibility of the prejacent with an epistemic conversational background. The plausibility of a possible worlds semantic account for apparire, is consistent with the fact that the verb seems to work as an operator at the propositional level. As noticed by Faller (2002, pp. 10-115), the so called challengeability test (Palmer 2001, Sweetser 1990), which consists in questioning, doubting, or rejecting the meaning of an element is the most reliable test to check if an evidential contributes to the meaning of the main proposition or not:

4. Guardando all'affrettata stesura del colore, il dipinto appare incompleto

"Looking at the inaccurate application of the colour, the painting appears to be incomplete"

a. Is that so?

b. I agree

c. I don't believe it

\footnotetext{
${ }^{6}$ The interlinguistic usefulness of Relative Modality for a context dependent semantic account of different modal flavours has been highlighted in various studies (e.g. Rocci 2012, Faller 2011).
}

(C) Elena Musi, Informal Logic, Vol. 34, No. 4 (2014), pp.417442. 
The antagonist's reactions in 4(a-c) can be interpreted both as commenting on the truth of the proposition (the painting is incomplete) or that of the modal proposition (the painting appears to be incomplete). The antagonist could disagree with the fact that the way in which the colour is applied on the canvas entails that the painting is probably incomplete, claiming for example that an unrefined application of colour is a typical feature of that painter's style. This property is inherent to evidential verbs: the use of a verbum putandi like 'to think' would not allow such an ambiguity, leaving only the truth of the embedded proposition as questionable.

The verb apparire is not perfectly equivalent to a verbum putandi due to its evidential nature. The use of the verb next to an explicit declaration of the lack of sources of information on the part of the speaker, though acceptable, would in fact sound weird:

5 a. ?Non so perché, ma il dipinto appare incompleto

"?I do not know why, but the painting appears to be incomplete

b. Non so perché, ma penso che il dipinto sia incompleto

"I do not know why, but I think the painting is incomplete"

Another argument in support of the evidential character of the verb is its compatibility only with the expression of indirect evidentiality: as noticed with regard to example 2, differently from a verb like vedere, 'to see', the verb apparire never refers to a state of affairs where the experiencer has direct access to an event which he perceives visually at the moment of speaking.

As argued in possible worlds semantics, the modalized sentence is false only when the ontological relation between the proposition and what the speaker knows is negated. This test shows that apparire is indeed an operator at the propositional level, whose truth value is connected to its inferential relation with the sources of information, but does not explain which elements the speaker's degree of commitment depends on.

The definition of the argument $\mathrm{B}_{\text {Dox }}$ as a set of presumptions reveals, in fact, the modal epistemic value intrinsic to the verb: apparire, compared to essere ('to be') assigns a lesser degree of certainty to the truth of what is asserted; in other words, even if the reviewer commits himself to the truth of the proposition, he signals at the same time that the uttered proposition expresses a state of affairs whose likelihood is judged on the basis of the

(C) Elena Musi, Informal Logic, Vol. 34, No. 4 (2014), pp.417442. 
data available to him $\left(\mathrm{x}_{1}\right)$, his knowledge and reasoning capacities $\left(\mathrm{B}_{\text {Dox }}\right)$.

Formally speaking, this epistemic stance implies a semantic representation of apparire as a quantifier over possible worlds which is restricted by a conditional clause concerning the type of $\mathrm{x}$ the speaker is relying on and their relevance for the operation of classification. This conditional restriction selects the set of possible worlds in which the inferential relation between the sources of information and the asserted proposition is consistent: sentence 4 could, for example, be paraphrased as "provided that we have only visual evidence available and that the way in which colour is applied on the canvas is relevant in deciding if a painting has been finished, the not accurate application of the color is a signal that the painting was probably not finished". The degree of possibility depends on the type of data at disposal and on our cognitive ways of experiencing the world.

As shown in the next section the uncertainty conveyed by modal expressions correlates with the awareness, pointed out by fuzzy logic, that human reasoning is approximate rather than exact, especially when based on perceptual data.

\section{Defeasible arguments and reasoning from categorization}

To exemplify the mechanisms underlying fuzzy logic, Zadeh (1975, p. 408) presents the following syllogism:

\section{$A_{1}:$ Most men are vain \\ $A_{2}$ : Socrates is a man \\ $A_{3}$ : It is likely that Socrates is vain \\ $A^{\prime}{ }_{3}$ : it is very likely that Socrates is vain}

The consequents $\mathrm{A}_{3}$ and $\mathrm{A}_{3}{ }_{3}$ are both possible consequents of premises A1 and A2 depending on the degree of approximations of the term most. Since the majority of men (but not all) are vain and Socrates is a man, it is possible/almost certain (but not certain) that Socrates is vain too. ${ }^{7}$ Similarly, the evidential-

\footnotetext{
${ }^{7}$ It has to be noted that already in his Posterior Analytics Aristotle speaks about syllogisms "epì tò polú", 'for the most part' (Lat. "plerumque"): "Every syllogism proceeds through premises which are either necessary or usual [epì tò polú]; if the premises are necessary, the conclusion is necessary too; and if the premises are usual, so is the conclusion" (I, 87b25). As underlined by Rescher (1964, p. 170) Aristotle's theory of modal reasoning has its conceptual roots in the theory of scientific inference.
}

(C) Elena Musi, Informal Logic, Vol. 34, No. 4 (2014), pp.417442. 
epistemic meaning of apparire signals that the proposition $p$ refers to a possible state of affairs whose plausibility depends on the reliability of the SoAs (state of affairs) expressed in the premises, which are subjective in the sense that they are valid as far as the speaker knows.

Even if direct sight is considered one of the most certain means of knowledge (Sweetser 1990, p. 33), inference based on perceptual data (e.g. 2, 3) can be misleading due to the fact that "a perceived object only approximates material objects, and that it may change its appearance as our perceptual information changes." (van der Does and van Lambalgen 2000, p. 11). The fact that perceptions depend on the perceiver's perspective and thus can be deceiving, is clearly shown by some occurrences of apparire:

6. Le cavità che attraversano la composizione hanno la potenzialità di apparire come tetri spazi neri o come superfici pienamente scintillanti, secondo la disposizione della fonte luminosa. (Review, Mostreinmostra, Exhibition: "Ben Ormense per un instabile equilibrio", Sacile)

"The cavities throughout the composition have the potential to appear as gloomy black spaces or as fully sparkling surfaces, according to the arrangement of the light source"

7. L'ambiente appare immutato nella sua consuetudine espositiva, un classicismo narrativo che traghetta lo sguardo attraverso i secoli. Arrivati a metà del corridoio d'entrata però, una struttura color rosso vivo regala nuovi interrogativi: è il Concetto spaziale di Lucio Fontana (1960), l'idropittura creata con tagli e buchi che apre la mostra. (Review, Mostreinmostra, Exhibition: "Burri e Fontana a Brera", Milano)

"The environment appears unchanged in its customary exhibition, a classical narrative that draws the gaze through the centuries. Once in the middle of the entrance corridor, however, a bright red structure gives new questions: it is the Lucio Fontana's spatial concept (1960), the water-based painting with cuts and holes that opens the show"

In example 6, the "omniscient reviewer" explains that cavities could appear differently to visitors depending on the light's conditions. In 7, instead, the "filter" influencing the perception is not external, but part of the perceptual experience itself: if at

(C) Elena Musi, Informal Logic, Vol. 34, No. 4 (2014), pp.417442. 
Interface

the beginning of the visit the environment seems unchanged, the appearance of Fontana's work of art changes the situation. Generally speaking, our perception is affected by imprecise visual information and lack of knowledge which make us draw plausible, but not absolutely valid inferences. In argumentation theory, this gap between the real object and the perceived object underlying appearances, is accounted for in terms of defeasible argumentation schemes. In particular, Walton, Reed and Macagno (2008) describe the standpoints asserted by inference from visual data as conclusions driven from the so called appearance argument scheme:

\section{Premise: This object looks like it could be classified under verbal category $C$. Conclusion. Therefore, this object can be classified under verbal category C. (Walton, Reed and Macagno 2008, p. 345)}

As observed by the above scholars, the argument from appearance dates back to Greek philosophers as an instance of plausible reasoning, that is to say the reasoning "based on appearances, meaning propositions that appear to be true and have standing as acceptable premises in a rational inference used to draw a conclusion, even though the inference can later turn out to be erroneous" (Walton 2006, p. 320). Plausible reasoning does not include only reasoning based on observational data, but every argument based on generalizations subject to exceptions. In the light of this, it seems that apparire, due to its evidentialepistemic semantics, functions in its inferential uses as a marker indicating that the type of reasoning at work is a defeasible one: a proposition appears to the speaker to be true, even if he does not know it is veridical.

Data analysis has shown that apparire usually indicates what in Pragma-Dialectics is called symptomatic argumentation since "the property attributed to the referent in the argument is put forward as being a symptom of the property attributed to it in the standpoint" (Hitchcock and Wagemans 2011, p. 186). In particular, the process involved is that of classification where " $x$ appears to be $y$ " on the basis of the identification by the perceiver of some properties of $y$ in $x$. At this point, the research question I would like to answer is: which component does the defeasibility of the argumentative reasoning have its roots in?

In this regard, dealing with arguments from classification, Walton and Macagno (2010) state that the "Argument from Criteria to Verbal Classification" (which fits the kind of

(C) Elena Musi, Informal Logic, Vol. 34, No. 4 (2014), pp.417442. 
reasoning exploited in our case of study) is defeasible due to the generalization made in the major premise:

MAJOR PREMISE: If $X$ has the characteristics $A, B, C \ldots$ then $X$ is $Q$

MINOR PREMISE: Event or object $X$ has the characteristics A, $B, C$ CONCLUSION: Therefore, event or object $X$ is $Q$.

(Walton and Macagno 2010, p. 37)

One of the critical questions at issue is: what evidence is there that the characteristics $\mathrm{A}, \mathrm{B}, \mathrm{C}$ are sufficient conditions to classify $\mathrm{X}$ as Q? In fact, it would be possible that $\mathrm{X}$, even if showing the characteristics $\mathrm{A}, \mathrm{B}$, and $\mathrm{C}$ is not, in a real state of affairs, a member of the class Q. Following this scheme, the likelihood that the inferred proposition is true depends on the degree of defeasibility of the major premise. As explained in the next section, I consider the relevance of the characteristics for the operation of classification as a subjective, context-bound matter of the experiencer whose degree of commitment to the undergone categorization is mirrored by the semantic structure of the inferential connections on which the locus is based. To understand the condition of the validity of these connections, I think it is useful to draw attention to the mechanisms enabling the inferential relation itself. The fact that some characteristics are interpreted by the speaker as signs from which to infer a possible categorization seems to indicate that our processes of meaning construction work through principles of analogy and similarity, more than on a principle of identity. Recognizing graduality and subjectivity as properties inherent to categorization has been essential to explaining linguistic phenomena grounded on perception - such as metaphor. As underlined by Albertazzi (2010) in her studies about perception and inference, it is impossible to account for metaphorical categorization in substantial terms (e.g., by genus and species) even though "when subjective experiences are given names which also apply to perceptual facts, this does not happen in a random fashion" (p. 360).

The inferences from objective reality at the basis of the expression of appearances pertain to the epistemological relationships between categories of mind and categories of the real world. As underlined by Lakoff (1982), categories of the mind do not directly mirror categories which are supposed to

(C) Elena Musi, Informal Logic, Vol. 34, No. 4 (2014), pp.417442 . 
Interface

exist objectively in the world, but they depend on "experiential aspects of human psychology" (Lakoff 1982, p. 99).

The evidential-epistemic uses of the verb apparire reveal that the speaker qua experiencer is aware that perception is not the result of an inference from objective reality but it is the product of an awareness process based on external visual data.

This non-objectivist view of categories has been deeply supported by prototype theory which was elaborated in the mid1970 s as a reaction to the fact that "much work in philosophy, psychology, linguistics and anthropology assumes that categories are logical bounded entities, membership in which is defined by an item's possession of a simple set of criterial features, in which all instances possessing the criterial attributes have a full and equal degree of membership" (Rosch and Mervis 1975, pp. 573-574).

The basic proposal of the theory is to focus on the degree of representativeness of members of a category rather than on the membership status itself, due to the fuzzy boundaries characterizing categories. This perspective is especially fruitful for the analysis of the inferential epistemic meanings of apparire where the speaker is asserting the belonging of what he perceives to a category, but he is at the same time questioning the relevance of the reasons underlying his operation of classification.

The notion of prototype from psychology has developed in different directions depending on the field. As far as linguistics is concerned, prototype theory has developed in contrast to an idea in transformational grammar, namely that semantic structure in natural languages can be studied as a language-specific module independently from the encyclopaedic knowledge that people possess and that the semantic extension of a concept may be defined through a list of features indispensable for its definition (Geeraerts 1989). The interrelation of encyclopaedic and semantic knowledge envisaged by prototype theory turns out to play an important role at the argumentative level: readers are able to understand the author's use of specific terms to describe what appears to him in virtue of the sharing of some encyclopaedic world knowledge which is present in the author's lexicon.

Following Geeraerts (1989, pp. 146-147), prototypical categories are characterized by four essential properties: absence of a set of criteria of necessary and sufficient attributes, presence of a radial set of clustered and overlapping meanings, degrees of representativeness, and blurred edges.

(C) Elena Musi, Informal Logic, Vol. 34, No. 4 (2014), pp.417442. 
One of the most debated aspects of prototype theory pertains to the parameters used to define the degrees of representativeness of a member. The most representative exemplar of the category (prototype) is conceived as the one that has the majority of common features with the other members of the category and shares the minor number of features with members belonging to other categories. The prototype is hence considered as the most salient member since it presents most of the features normally attributed to a category.

However, the motivations at the basis of the identification of the central traits of a category can be cognitive, cultural, as well as perceptual and are, hence, hard to identify without making reference to people's judgements. For this reason, prototypes have been operationally defined, collecting the people's opinions about the goodness of membership in a category (Rosch 1978). The occurrences of the verb apparire are instances of judgments of the experiencer about the membership of the perceived object in a category: the sources of information semantically presupposed by apparire can be conceived as the traits that the experiencer considers relevant for its reasoning from classification. On the other hand, the uncertainty expressed by the epistemic value of the verb gives the reader information about the saliency that the experiencer attributes to those traits.

The explanatory power of the prototype model for an argumentative account of evidentiality and epistemic modality lies in the recognition of a link between the strength of arguments from definition and the quality of the characteristics involved: if the features attributed to the object are perceived by the experiencer as central traits of the category, their belonging to the category will be presented as more certain than if they are peripheral.

As noted by Walton and Macagno (2010), in our everyday experience we have to rely on defeasible evidence and limited knowledge in order to categorize what we perceive. When we visit an exhibition our reasoning in approaching works of art functions as a heuristic, a temporary way to solve problems of categorization. In this perspective, the basic principles of prototype theory provide a useful tool to analyse heuristics of this kind.

(C) Elena Musi, Informal Logic, Vol. 34, No. 4 (2014), pp.417442. 


\section{The argument from prototype definition}

Interface

The Argumentum Model of Topics (Rigotti and Greco, 2010) is an approach to the study of argument schemes based on the combination of a procedural and a material component: "The procedural component is based on the semantic-ontological structure [locus], which generates the inferential connection [maxim] from which the logical form of the argument is derived; the material component integrates into the argument scheme the implicit and explicit premises bound to the contextual common ground" (Rigotti and Greco 2010, p. 489). In particular, the material component includes two components: endoxa (major premise), which makes reference to common knowledge, and datum (minor premise), a factual premise which specifies the realization in discourse of the minor premise of the logical form.

Compared to other approaches to argument schemes (e.g. Pragma-Dialectical approach), the AMT Model, taking into account the level of material premises, makes it possible to explain the applicability of the inferential connection at work (maxim) to the actual context of the argumentation. The AMT Model, guaranteeing the context-boundedness of arguments, is a useful tool to analyse the argument schemes under question: the degree of defeasibility of the standpoint depends on the implementation of the maxim in the material component. Moreover, the partition of the material component into two levels mirrors the semantic components at the basis of apparire's semantic structure which play a major role in the building up of inferences: the endoxa corresponds to the expression of the perceiver's knowledge about the relevance of the data in drawing the inference (see $\mathrm{B}_{\text {Dox }}$ section 3 ) and the datum to the eventuality experienced by the perceiver.

In this section I propose two argumentative reconstructions of apparire's inferential uses modeled on the AMT Y-like structures.

Reconstruction $a$ :

8. Mirko Basaldella è invece più stilizzato, più sintetico nell'esprimersi della sua sensibilità d'artista. Suoi sono il Mino danzante (1967) e il Sacerdote (1969): il primo presenta forme accostate lineari e rotonde, il secondo più ieratico e solenne, appare quasi un totem nel suo costruirsi piano su piano in scaffalature bronzee che lasciano però al loro interno delle aperture a mezzaluna

(C) Elena Musi, Informal Logic, Vol. 34, No. 4 (2014), pp.417442. 
quasi a suggerire che la salita verso un qualsiasi credo è comunque composta da una globalità di linee che si intersecano fra loro e dove possono dipanarsi le vicende umane. (Review, Mostreinmostra, Exhibition: "I Basaldella. Dino, Mirko e Afro", Udine)

"Mirko Basaldella is more stylized, more concise in expressing his sensibility as an artist. The Dancing Mino (1967) and Priest (1969) are two of his works: the first presents linear and round juxtaposed forms, the second more solemn and hieratic, [it appears almost as a totem] $]_{\text {proposition }}$ [in his building up floor upon floor of bronze shelving which, however, leaves within themselves openings with a crescent shape as if to suggest that the ascent to any creed is still made up of a whole series of lines that intersect each other and where they can unravel human stories] $]_{\text {source of information". }}$

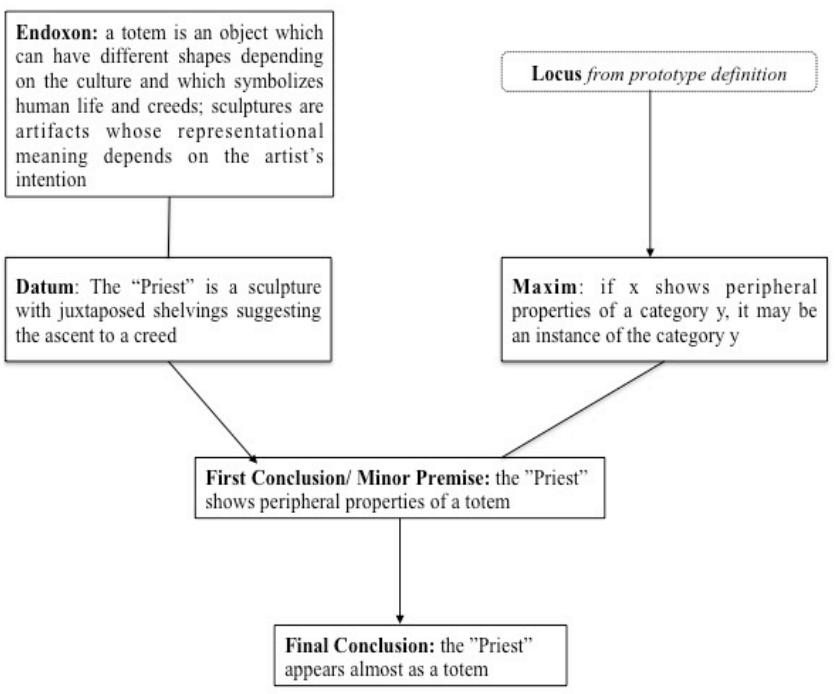

Figure 1. Locus from prototype definition

In 8 , the speaker, being exposed to the work of art entitled "Priest" in the exhibition, abductively infers that the sculpture by Mirko Basaldella is a totem. Looking at the description of the shape of the "Priest", it is plausible to claim that the speaker is exploiting an argument from definition by parts and whole relying only on visual sources of information. However, the relative proposition through which the speaker further specifies the juxtaposition of the bronze shelves as suggesting the ascent

(C) Elena Musi, Informal Logic, Vol. 34, No. 4 (2014), pp.417442. 
Interface

to a creed, makes clear that his process of categorization is based on the identification both of concrete and abstract properties. The speaker makes reference to a supposed function of the forms because a totem is a superordinate highly culturally bounded category which can be represented by different types of objects with different shapes, depending on the cultural context. Hence, visual data, although being immediately accessible through the sense of sight, are very poor elements for classifying an object as a "totem". On the other hand, functional properties are more central traits of the category since they are intercultural and they normally belong to intersubjective world knowledge. Even if relying both on sensorial and functional clues justifying the inclusion of the "Priest" in the category "totem", the standpoint inferred from this argument scheme from definition is presented by the speaker as quite defeasible through the addition of the adverb quasi ('almost') after apparire.

The low level of commitment expressed by the speaker regarding the uttered proposition mirrors his awareness of an addition filter imposed on perception by the very nature of artistic experiences: when seeing a work of art, the perceptual process of the visitor is mediated by the artist's representative intentions which cannot in any way be directly accessed by the visitor. Since the "Priest" is indeed an artifact, there could be a non-measurable gap between the function of the object as perceived and its function as conceived by the artist. In the light of this, the functional properties of the totem recalled by the author function in the proposed argumentative reconstruction as peripheral properties revealing that the saliency of the trait is highly context-bounded.

Reconstruction $b$ :

9. Visitare una monografica su Piet Mondrian, oggi, non è cosa facile. Richiede uno sforzo. Quella pittura pura, cosi maledettamente oggettiva, scientifica, sembra lontana dalla sensibilità attuale, maggiormente incline a forme artistiche più espressioniste o a un astrattismo irrazionale, legato a oscuri automatismi psicologici. Ci sembra più agevole fruire di un'arte che induca turbamento più che riflessione, coinvolgimento più che ragionamento. Forse ciò è dovuto a una presunta frattura, operata da un certo punto in poi, tra arte $e$ scienza. E l'arte di Piet Mondrian sembra voler recuperare questa lacerazione. Appare quindi una bella scommessa quella fatta dal Centre Pompidou a Parigi,

(C) Elena Musi, Informal Logic, Vol. 34, No. 4 (2014), pp.417442. 
promotore di una grande retrospettiva sul maestro olandese, curata da Brigitte Leal. (Review, Mostreinmostra, Exhibition: "Mondrian/De Stijl”, Paris)

"[To visit a monograph about Piet Mondrian, today, is not easy. It requires an effort. That pure painting, so damned objective and scientific, seems far away from the current sensitivity, which is more inclined to expressionist artistic forms or to an irrational abstraction tied to dark psychological automatisms. It seems easier to benefit from an art that induces perturbation rather than reflection, involvement more than reasoning. Perhaps this is due to an alleged breach, made from a certain point onwards, between art and science. And the art of Piet Mondrian seems to want to recover this laceration $]_{\text {sources of }}$ information . [This, therefore, appears a real bet, the one made by the Centre Pompidou in Paris $]_{\text {proposition }}$, the promoter of a retrospective on the Dutch master, curated by Brigitte Leal".

The argumentation exploited by the speaker in order to infer that the monograph about Piet Mondrian is a real bet is based on a Datum which rather than being a piece of evidence is a prediction supported by a sub-argumentation. For this reason, two Y-reconstructions are proposed. The first reconstruction mirrors the reasoning through which the speaker forecasts that the monograph will attract few visitors on the basis of his knowledge about people's tastes. The use of the impersonal form in describing the 'current sensitivity' with regard to art makes us understand that the writer is reporting the goals driving peoples' decision-making process for going to an exhibition.

In other words, the author is reconstructing the pragmatic reasoning underlying the event "going to an exhibition" which is intentionally caused by human subjects on the basis of the realization of their purposes. The intentionality trait called into question makes us understand that the locus exploited by the author is that from final cause which, different from the locus from the efficient cause, necessarily belongs to the ontological frame of human action. This locus, as shown in what follows, "focuses on the relation connecting the end (goal, purpose) of an action with the action itself" (Rigotti 2008, p. 566):

(C) Elena Musi, Informal Logic, Vol. 34, No. 4 (2014), pp.417442. 


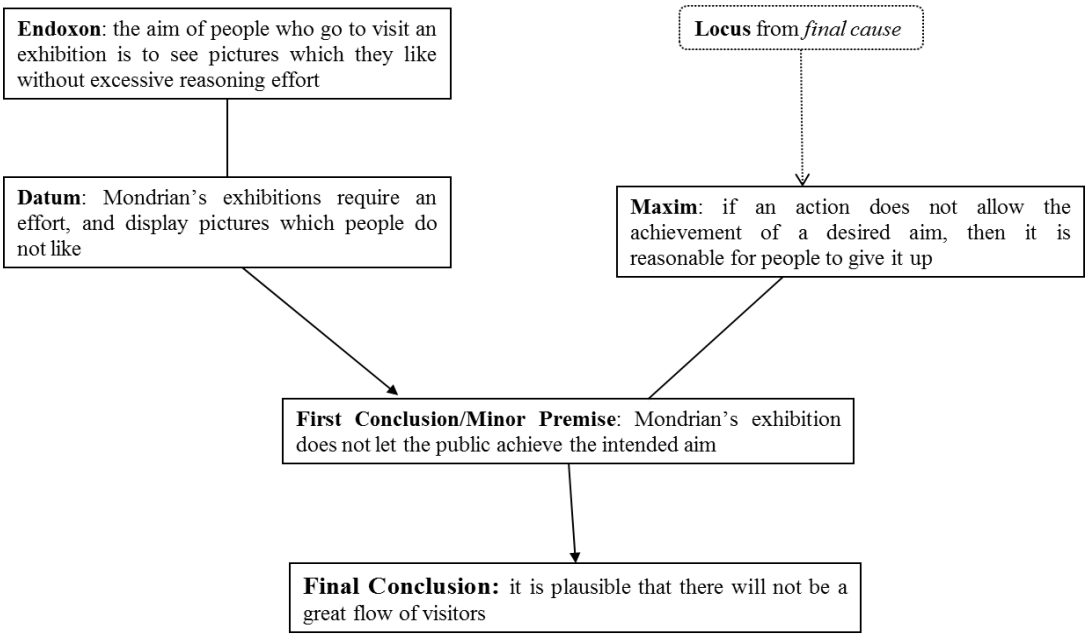

Interface

Figure 2. Locus from the final cause

The word "bet" is defined as designating "an act of risking a sum of money against someone else's on the basis of the outcome of a future event, such as the result of a race or a game" (The New Oxford Dictionary of English). In contemporary English and Italian the term is metaphorically used to generally encode "risky events", even if the feature "risky" is not per se distinctive in the semasiological structure of "bet".

The standpoint is an argumentatively justified presumption which becomes the minor premise of the following argumentative reasoning from prototype definition:

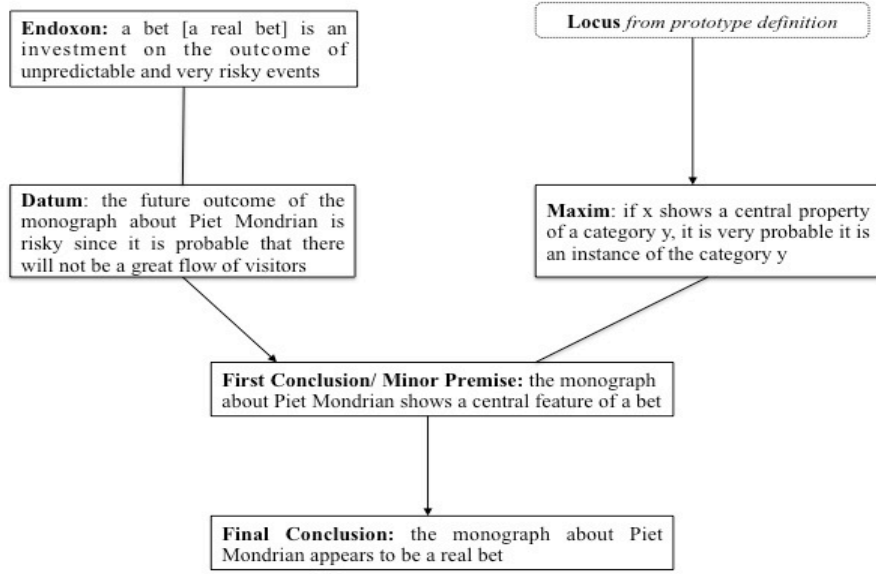

Figure 3.. Locus from prototype definition

(C) Elena Musi, Informal Logic, Vol. 34, No. 4 (2014), pp.417442. 
"risky" is not per se distinctive in the semasiological structure of "bet". The exhibition of Piet Mondrian shares some features with the frame of wagering to which the concept of "bet" belongs (in FrameNet the wagering frame is defined as follows: "A gambler commits an asset to a prediction that an uncertain situation will have a particular outcome (or class of outcomes)"): the organizers have invested some money on its preparation and the flow of visitors in not measurable at the moment of speaking and, thus, uncertain.

However, the consecutive connective "therefore", which links the sources of information to the proposition containing apparire, signals that the speaker classifies the exhibition as a bet primarily because of its risky outcome, using the term metaphorically. Moreover, the speaker's definition of the monograph about Piet Mondrian not only as a bet, but as a real bet (bella scommessa) entails that risk is conceived by the speaker as a non-discrete concept whose graduality affects the belonging of an event to the category of bet. Since the more risky the outcome of an event is, the more intense is a bet stipulated on its realization, the low probability of the happening of an event is a central property of the category "bet". Therefore, the forecast expressed in the Datum determines that the exhibition's belonging to the category of a bet is well grounded.

The final conclusion in 9. is less defeasible than the one in 8 . because of the different quality of the properties called into question in the maxim (peripheral vs. central properties).

Nevertheless, the use of apparire instead of the verb to be recalls for us the uncertain veridicality of the conclusion, inherited from the defeasibility of the Datum which is a presumption.

\section{Conclusion}

The analysis of the semantic-argumentative interface sketched out in this paper has shown the relevance that a semantic theory may have for a deep understanding of defeasible reasoning. On the backdrop of Congruity Theory, I have formalized the semantic structure of the Italian verb of appearance apparire in its inferential uses: the proposition inferred is the result of a set of information sources and of a set of background presumptions which are both arguments linguistically presupposed by the verb. At the argumentative level, these two lexical arguments function as premises from which the conclusion is drawn. The verb

(C) Elena Musi, Informal Logic, Vol. 34, No. 4 (2014), pp.417442. 
apparire, due to its epistemic nature, marks not only the presence of an inferential reasoning, but signals also that the kind of reasoning at work is a defeasible one. As shown by fuzzy logic, the degree of defeasibility of the conclusion is directly proportional to the degree of defeasibility of the premises.

As far as our data are concerned, the arguments exploited in defeasible reasoning have been shown to be symptomatic arguments and, in particular, arguments from definition. As indicated by the gap between perceived entities vs. real entities in our experience of the world, perceivers do not classify objects on the basis of a set of predefined specific features, but their process of categorization is gradual, subjective, and affected by multiple factors. In the two y-like structures proposed as exemplary argumentative reconstructions, the defeasible premise is the Datum. The advantage offered by the application of prototype semantic theory is the identification of a connection between the degree of defeasibility of the conclusion and the quality of the properties taken into account in the maxim (central vs. peripheral properties).

In other words, the defeasibility of the standpoint reflects the perceiver's judgement on the goodness of membership about what he sees in a category. Starting from the methodological issue addressed in this paper, further research is needed to test if the locus from prototype definition is an ontological relation used in inferential configurations activated by other evidentialepistemic verbs cross-linguistically.

Acknowledgements: I would like to thank the two anonymous reviewers, Johanna Miecznikowski, Andrea Rocci Giovanni Damele, Fabrizio Macagno and Michael Baumtrog for their very helpful comments and suggestions on previous drafts of this paper.

\section{References}

Aristotle (1960). Posterior Analytics. Edited and translated by H. Tredennick. Cambridge Mass.: Harvard University Press. Albertazzi, L. (2010). The Perceptual Roots of Metaphor. In: L. Albertazzi, G. van Tonder and D. Vishwanath (Eds.), Perception Beyond Inference: The Information Content of Visual Processes (pp. 345-390), Cambridge Mass.: MIT Press.

(C) Elena Musi, Informal Logic, Vol. 34, No. 4 (2014), pp.417442. 
Bigi, S. and S. Greco Morasso (2012). Keywords, frames and the reconstruction of material starting points in argumentation. Journal of Pragmatics 44, 1135-1149.

Col, G. (2006). Appear, seem et look: «perception » et « construction » des apparences. Corela. Numéros thématiques| Les verbes d'apparence.

Cornillie, B. (2009). Evidentiality and Epistemic Modality. On the Close Relationship Between Two Different Categories. Functions of Language 16.1, 44-62.

Diewald, G. and E. Smirnova (2010). The Linguistic Realization of Evidentiality in European Languages. Berlin/New York: Mouton de Gruyter.

Does, J. van der and M. van Lambalgen (2000). A Logic of Vision. Linguistics and Philosophy: An International Journal 23, 1-92.

Douven, I. and S. Verbrugge (2010). The Adams family. Cognition 117, 302-318.

Eemeren, F. H. van (2010). Strategic Maneuvering on Argumentative Discourse. Amsterdam/Philadelphia: John Benjamins.

Eemeren, F. H. van and R. Grootendorst (2004). A Systematic Theory of Argumentation: The Pragma-Dialectical Account. Cambridge: Cambridge University Press.

Faller, M. (2002). Semantics and Pragmatics of Evidentials in Cuzco Quechua. PHD Dissertation. Stanford University.

Faller, M. (2011). A possible worlds semantics for Cuzco Quechua evidentials. In: N. Li and D. Lutz (Eds.), Proceedings of SALT 20 (pp. 660-683), Ithaca: Cornell University Press Publications.

Geeraerts, D. (1989). Prospects and problems of prototype theory. Linguistics 27.4, 567- 612.

Gisborne, N. (2007). A History of English Evidential Verbs of Appearance. English Language and Linguistics 11.1, 1-29.

Hale, K. and S.J. Keyser (2002). Prolegomenon to a Theory of Argument Structure. Cambridge (Mass.): MIT Press.

Harman, G. (1965). The Inference to the Best Explanation. Philosophical Review 74, 88- 95.

Hitchcock, D. and J. Wagemans (2011). The Pragma-dialectical account of argument schemes. In: E. Feteris, B. Garssen and F. Snoeck Henkemans (Eds.), Keeping in Touch with Pragma-Dialectics (pp. 185-206), Amsterdam/Philadephia: John Benjamins,

(C) Elena Musi, Informal Logic, Vol. 34, No. 4 (2014), pp.417442. 
Interface

Josephson, J.R. and S.G. Josephson (1994). Abductive Inference: Computation, Philosophy, Technology. Cambridge: Cambridge University Press.

Kratzer, A (1981). The Notional Category of Modality. In: H.J. Eikmeyer, H. Rieser. (Eds.), Words, Worlds, and Contexts: New Approaches in Word Semantics (pp. 38-74), Berlin/New York: Walter de Gruyter.

Kratzer, A. (2012). Modals and Conditionals. New and Revised Perspectives. Oxford: Oxford University Press.

Lakoff, G. (1982). Categories and cognitive models. Berkeley Cognitive Science Report no. 2. Berkeley: Institute for Human Learning.

Miecznikowski, J., A. Rocci and G. Zlatkova (2013). Le funzioni inferenziali e polifoniche dell'avverbio epistemico italiano forse. In: D. Pirazzini, A. Schiemann (Eds.), Dialogizität in der Argumentation. Eine multidisziplinäre Betrachtung (pp. 201-230). Frankfurt a. M.: Peter Lang.

Miecznikowski, J., L'argomentazione nelle recensioni online. To appear in: B. Gili Fivela, E. Pistolesi and R. Pugliese, Parole, gesti, interpretazioni. Studi linguistici per Carla Bazzanell . Roma: Aracne.

Miecznikowski, J. and G. Zlatkova, Italian sembra/pare vs. sembrerebbe/parrebbe: modal, evidential and argumentative aspects. To appear in: Selected Papers of the International Conference 'Chronos 9', Université Paris-Diderot - Paris 7, 24 September 2009.

Palmer, F. (2001). Mood and Modality. Cambridge: Cambridge University Press.

Pustejovsky, J. (1995). The Generative Lexicon. Cambridge (Mass.): MIT Press.

Rescher, N. (1964). Aristotle's Theory of Modal Syllogisms and its Interpretation. In: M. Bunge (Ed.), The Critical Approach to Science and Philosophy (pp. 152-177). London: The Free Press of Glencoe.

Rigotti, E. (2005). Congruity theory and argumentation. Argumentation in Dialogic Interaction, 75-96.

Rigotti, E. (2008). Locus a causa finali. In: G. Gobber, S. Cantarini, S. Cigada, M. C. Gatti and S. Gilardoni (Eds.), Special Issue of L'analisi linguistica e letteraria, 559-576.

Rigotti, E. and S. Greco (2010). Comparing the Argumentum Model of Topics to Other Contemporary Approaches to Argument Schemes: The Procedural and Material Components. Argumentation 24.4, 489- 512.

(C) Elena Musi, Informal Logic, Vol. 34, No. 4 (2014), pp.417442. 
Rigotti, E. and A. Rocci (2001). Sens - non-sense - contresens. Studies in Communication Sciences 1, 45-80.

Rigotti, E., A. Rocci and S. Greco (2006). The semantics of reasonableness. In: P. Houtlosser and A. van Rees (Eds.), Considering Pragma-Dialectics (pp. 257-274). Mahway, NJ: Lawrence Erlbaum Associates.

Rocci, A. (2005). La modalità epistemica tra semantica e argomentazione. Milano: ISU.

Rocci, A. (2012). Modality and argumentative discourse relations: a study of the Italian necessity modal dovere. Journal of Pragmatics 44, 2129-2149.

Rocci, A. (2013). Modal conversational backgrounds and evidential bases in predictions: the view from the Italian modals. In: K. Jaszczolt and L. de Saussure (Eds.), Time: Language, Cognition and Reality, Oxford: Oxford University Press.

Rosch, E. (1978). Principles of Categorization. In: E. Rosch and B.B. Lloyd (Eds.), Cognition and Categorization, Hillsdale, N.J: Lawrence Erlbaum Associates.

Rosch, E. and C.B. Mervis (1975). Family Resemblances: Studies in the Internal Structure of Categories. Cognitive Psychology 7, 573-605.

Sweetser, E. 1990. From Etymology to Pragmatics. Cambridge: Cambridge University Press.

Walton, D.N. (2001). Abductive, presumptive and plausible arguments. Informal Logic 21. 2, 141-169.

Walton, D.N. (2006). Argument from Appearance, A New Argumentation Scheme. Logique et Analyse 195, 319-340.

Walton, D.N. and F. Macagno (2010). Defeasible Classifications and Inferences from Definitions". Informal Logic 30. 1, 3461.

Walton, D.N., C. Reed and F. Macagno (2008). Argumentation Schemes, Cambridge: Cambridge University Press.

Zadeh, L.A. (1975). Fuzzy logic and approximate reasoning. Synthese 30.3-4, 407-428.

(C) Elena Musi, Informal Logic, Vol. 34, No. 4 (2014), pp.417442. 